\title{
Incorporating Economic Cost Data in Water Resources Modelling
}

\author{
W.R. Godoy ${ }^{a}, \underline{\text { R. Brown }}{ }^{a}$, K. Austin ${ }^{a}$, L. van Raalte ${ }^{a}$, S. Sonnenberg ${ }^{\text {b }}$ and M. Lynch ${ }^{c}$ \\ a. Jacobs, 452 Flinders Street, Melbourne, Australia \\ b. Department of Environment, Land, Water and Planning, 8 Nicholson Street, Melbourne, Australia \\ c.South Gippsland Water, 14-18 Pioneer St, Foster, Australia \\ Email: Rachel.Brown@jacobs.com
}

\begin{abstract}
Victoria's water plan presents a number of challenges and opportunities relating to the planning and management of water resources. One such opportunity is to incorporate the cost impact on the community resulting from urban water restrictions. Water restrictions are a management tool commonly employed by urban water corporations to ration supplies during low water availability and therefore reduce water demands in a system. In Victoria, the implementation of restrictions is described within a Drought Preparedness Plan developed by each urban water corporation, which is system-specific depending upon local catchment climate, storage capacity and dead storage assumptions, seasonal demands and the assumed level of service over a long term planning period.
\end{abstract}

The Victorian Government has long used water resources models to inform long-term water resources planning and short-term drought response but the economic assessment of such scenarios to-date has been implemented using post-processed modelling results. The lack of integration between costs and flow means that the ability to evaluate alternative management options is tedious and does not provide a reliable and convenient approach for repeating cost-flow calculations, particularly in cases when multiple model runs are required. Moreover, as water resources models become more sophisticated and are developed over time by different modellers, the flow attributes that were once relied upon in previous economic assessments may no longer be appropriate given changes in the cost-flow assumptions.

This paper presents a case study in which an integrated hydrology-economics model has been developed in order to exploit urban customers' willingness to pay (WTP) to forego water restrictions. This work is presented as a proof-of-concept as applied to the REsource ALlocation Model (REALM) modelling package and demonstrated using a long-term planning case study in the Lance Creek Water Supply System. South Gippsland Water (SGW) currently operates the Lance Creek system to supply a number of small Victorian coastal towns using surface water resources harvested from Lance Creek. To date, the planning efforts have focused solely on this local resource but soon these efforts will need to consider additional hydrologic and economic considerations once the system is connected to the Melbourne Water Supply System. For instance, one consideration would be assessing the cost of foregoing water restrictions against the cost of supply from Melbourne.

A REALM model of the Lance Creek system was recently updated to support the preparation of SGW's Urban Water Strategy and is used for this case study. The REALM model runs over a 103-year period on a monthly time step assuming medium climate change hydro-climatic conditions projected at 2040. The unit cost values have been sourced from a review of Australian urban centres that assessed household WTP to avoid water restrictions. Five modelling scenarios are examined which consider different levels of access to the Melbourne system. The results show the marginal change in economic cost in terms of urban water restrictions, cost of water from Melbourne, and environmental cost in each case. The key finding from this work is that there is a cross-over point between the cost of restrictions and cost of water from Melbourne which will be a critical factor in future water resources planning. In general, the study shows that REALM is capable of incorporating economic cost data and providing valuable hydro-economic insights in the management of water resources.

Keywords: Cost of urban water restrictions, integrated hydrology-economics model, REALM 


\section{INTRODUCTION}

Water resources planning typically aims to meet 'triple bottom line' targets i.e. environmental, social, and economic goals. In terms of the economic considerations, this ought to include both market-based costs that are readily quantifiable in monetary terms, such as physical infrastructure and operational costs, as well as non-market costs that are less easily monetised but are nonetheless real and borne by stakeholders such as the community and the environment. Whilst the use of water resource models such as REALM (Perera et al., 2005) and Source Rivers (eWater, 2017) help water corporations make important decisions about the timing of system augmentations and the implementation of water restrictions, the economic factors are not directly considered within these models.

Willingness to pay (WTP) is the foundation of the economic theory of valuation. WTP uses money as a metric to measure the value that an individual places on receiving a good or service. The present study seeks to exploit urban customers' willingness to pay to forego urban water restrictions. This willingness to pay for additional water is also reflected in consumer's WTP to avoid water restrictions. MJA (2017) undertook a review of economic studies that focused on water consumer's WTP to avoid the cost of urban water restrictions. MJA (2017) also made recommendations on the application of such work to towns in Victoria. This paper describes such costs in terms of two types of economic loss that result from urban water restrictions, viz. (i) the reduction in quantity of water that an individual is able to consume that otherwise would have been prepared to purchase; and (ii) the removal of choice over how water could have been used prior to water restrictions being introduced.

Water restrictions are commonly employed by urban water corporations to reduce water demands in a system during periods of low water availability. Victoria relies on urban water restrictions to achieve a reduction in the aggregate quantity of water consumed relative to times when there are no restrictions imposed. The effectiveness of this is dependent on the degree to which the restrictions affect consumptive behaviour. For example, under Stage 1 restrictions residential users are restricted to watering lawns on designated days and times, and under Stage 2 the watering of residential lawns is banned altogether. This would only affect individuals that have a lawn to water, and would only reduce total demand to the extent that these users actually reduce water use over a time period (and not simply apply an equivalent additional amount of water during "allowed" times). This has important implications for the extent to which restrictions give rise to the two types of economic loss mentioned above for different customer groups that are served by a water corporation.

Recent studies on integrated hydrology-economics modelling in Australia have focused on the economic value of improved environmental health and water re-allocations of irrigation water in the Murray-Darling Basin (MDB). Bennett et al. (2008) estimate the economic value of improved environmental health in three Victorian rivers (the Goulburn, Broken and Corangamite rivers). They designed and conducted surveys of river health attributes of native fish, riverside vegetation, native waterbirds and other animals, and water quality/recreational opportunities. The results were developed for human populations sampled within the catchment, out of the catchment and in Melbourne. Kirby et al. (2014) explore the impact of water re-allocations and climate change on flows available to the environment, irrigation diversions, and on the economic returns to irrigated agriculture in the MDB. They used an integrated hydrology and economics model to assess the annual variability of these system characteristics, and analyse the sensitivity at different levels of re-allocation and different climate change projections. Kirby et al. (2016) built on that earlier 2014 work to provide the first assessment of alternative management strategies (for both environmental water managers and irrigators) for responding to the combined effects of climate change and re-allocation of irrigation water to the environment.

In another related study, CIE (2010) assessed the benefits and costs to the community of alternative operating rules for a desalination plant for Sydney, Australia. The assessment focused on the impact that a desalination plant would have had on Sydney's storage levels and restrictions, had a plant been available at that time. CIE (2010) results show that the desalination plant would have allowed Sydney's storage levels to be maintained above 50\% full, thereby deferring the need to impose level 2 and level 3 urban water restrictions. Whilst CIE (2010) used a WATHNET model of the Sydney Water Supply System it is not clear if this model was modified to directly incorporate economic cost data or whether model outputs were used as part of a post-processing exercise to calculate costs.

This paper presents a case study in which an integrated hydrology-economics model has been developed in order to exploit urban customers' willingness to pay (WTP) to forego water restrictions. Whilst this work is aimed at demonstrating how economic costs could be incorporated into modelling, it is acknowledged that more work is required to develop system specific input variables before such results can be considered meaningful. The Lance Creek system case study is owned and operated by South Gippsland Water. This system has been chosen as it will be supplied conjunctively from local resources and the Melbourne Water 
Supply System and so decisions regarding water restrictions could be enhanced by incorporating hydrologic and economic considerations beyond those currently considered.

\section{ECONOMIC THEORY AND COST OF RESTRICTIONS}

Willingness to pay (WTP) is the foundation of the economic theory of valuation. WTP uses money as a metric to measure the value that an individual places on receiving a good or service. A complementary measure, Willing To Accept (WTA), measures the monetary compensation an individual would accept for the sacrifice of a good or service. Importantly, both WTP and WTA exist regardless of whether an individual actually pays for or receives a good or service. Prices provide a good indication of WTP and WTA when markets function well. Where they do not, market failures and inefficiencies cause prices to deviate and other techniques are required to estimate WTP/WTA such as choice modelling, contingent valuation, and the travel cost method, to name a few.

The use of mandatory water restrictions for demand management imposes a range of priced and non-priced costs on the community. The costs to households of urban water restrictions arise largely through the denial of opportunity to use water in ways that are most valued. All consumers are forced to constrain outdoor water use in the same way despite varying preferences and values for various types of outdoor use. This leads to significant costs for users who would be willing to pay for additional water, and an inefficient allocation of water resources (Productivity Commission 2011).

This willingness to pay for additional water is also reflected in consumer's WTP to avoid water restrictions. MJA (2017) undertook a review of economic studies that focused on water consumer's WTP to avoid the cost of urban water restrictions. MJA (2017) also made recommendations on the application of such work to towns in Victoria. This paper describes such costs in terms of the loss that results from urban water restrictions from (i) the reduction in quantity of water that an individual is able to consume that otherwise would have been prepared to purchase; and (ii) the removal of choice over how water could have been used prior to water restrictions being introduced. MJA (2017) explains that most urban water restriction regimes used in developed economies such as Victoria (Australia) use regulations to restrict, and in some cases ban, the use of water (e.g. on lawns), how watering is performed (e.g. not with a sprinkler), and the times that water can be used (e.g. specific days and hours). As mentioned in the introduction to this paper, the effectiveness of this is dependent on the degree to which the restrictions affect consumptive behaviour.

MJA (2017) also review 12 studies from across Australia that assessed household WTP to avoid water restrictions. Their review provides indicative unit values for WTP, subject to assumptions relating to the original studies and the local water restriction regimes from which the data were obtained. According to MJA (2017), the data was found to be broadly relevant to the Victorian context. On this basis it is considered appropriate for the purposes of incorporating non-market costs of urban water restrictions into water resources modelling. The unit values presented in MJA (2017) have been adopted and are presented in Section 0.

\section{THE STUDY AREA}

The Lance Creek system currently supplies the Victorian coastal towns of Inverloch, Wonthaggi and Cape Paterson, located in the South Gippsland catchment. The nearby towns of Korumburra, Poowong, Loch and Nyora will be connected to this system from 2019. This extended system has been used as the basis of the case study presented in this paper, as shown in Error! Reference source not found.. The hydrologic inputs to the Lance Creek REALM model include Lance Creek streamflow to Lance Creek Reservoir and the effects of evaporation and rainfall from the surface of the storage. The other service basins are used as balancing storages and are assumed to be covered. The model also includes a nominal supply from the Melbourne system in accordance with the supply rules considered in this study.

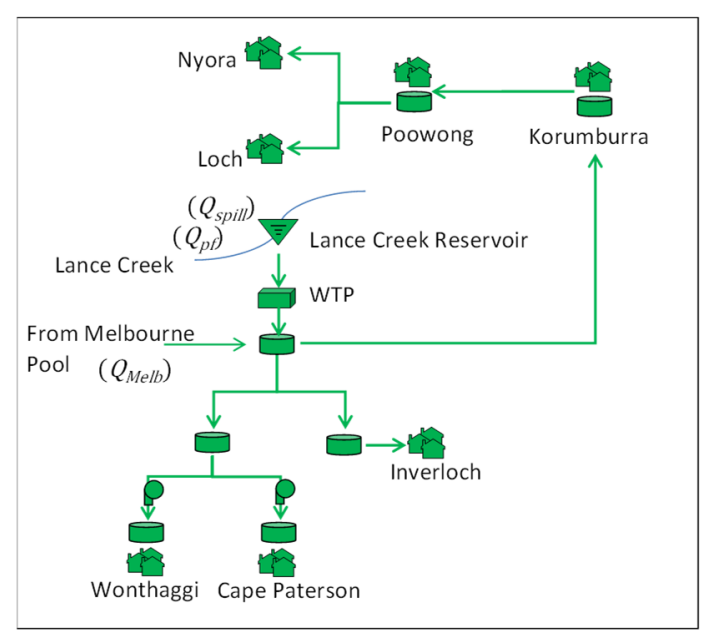

Figure 1. Lance Creek System (not to scale).

For reasons of brevity, the present study focuses on a single climate change scenario referred to as the medium 2040 climate change scenario as described in DELWP (2016a). This scenario is characterised by a $1.1^{\circ} \mathrm{C}$ 
increase in average daily temperature, $2.4 \%$ increase in annual potential evapotranspiration and $4.5 \%$ reduction in average annual rainfall in South Gippsland river basins. Urban demands represent 2040 levels of development and include incorporation of projected population increases for the towns of interest in combination with information on likely future water use under modified climate conditions as per Victoria in Future forecasts and DELWP (2016b). Based on population projections for the year 2040, it is assumed that there will be approximately 17,000 residential connections within the expanded Lance Creek system.

For the purposes of this case study, it is assumed that SGW will have access to 2 GL of entitlement from the Melbourne system in 2040, with a 15.2 ML/d pipeline capacity for the delivery of this water. This represents twice the current entitlement volume and a duplication of the existing delivery pipeline. It was also assumed for the present study that SGW would have access to $593 \mathrm{ML}$ on average for each $1 \mathrm{GL}$ of entitlement from the Melbourne system. This figure reflects the limitation to supply due to water availability. This volume is used in the model to constrain the annual allocation to SGW's entitlement water account in each year of the model period.

Three datasets are obtained from the model as input to economic cost calculations presented in Section 4 . Urban water restrictions ranging from level 1 to 4 , supply from Melbourne $\left(Q_{M e l b}\right)$, Lance Creek Reservoir spills to Lance Creek $\left(Q_{\text {spill }}\right)$, and passing flows to Lance Creek $\left(Q_{p f}\right)$.

\section{ECONOMIC DATA IN THE LANCE CREEK REALM MODEL}

\section{Cost of restrictions}

In the Lance Creek REALM model, the volume supplied to urban demands is restricted when the volume in Lance Creek Reservoir drops below a threshold level. For example, the threshold volumes for implementing different restriction levels at the start of summer (December) are shown in Error! Reference source not found. The model evaluates the restriction level each month throughout the year.

As described in Section 2, recent work undertaken by MJA has identified that water users are willing to payn order to avoid restrictions. A value reflecting the cost of restrictions can be incorporated directly into the REALM model with a total cost of restrictions based on the maximum restriction level reached each year in the model. The cost assumptions associated with each level of restriction applied in the model are provided in

The values presented in

reflect unit costs which have been incorporated into the REALM model. Equation (1) provides the cost of restrictions for the highest level of restriction in any given year $\left(\right.$ Cost $\left._{\text {rest }}\right)$ as the product of the total cost of restriction $(T C R)$ and the number of residential customer connections within the system $\left(C_{\text {resi }}\right)$.

Cost $_{\text {rest }}=T C R \times C_{\text {resi }}$

\section{Cost of supply from Melbourne}

For the Lance Creek system, the charges associated with the connection to the Melbourne system are assumed to include both fixed and variable components as provided in Error! Reference source not found. It is also assumed that SGW would be charged a fixed cost based on the entitlement volume regardless of the seasonal allocation or usage. These values are incorporated into the Lance Creek REALM model and are used to assess the total cost of water from the Melbourne system. Note for some systems, pumping costs could also be incorporated however these were not relevant for this case study.
Table 2. December restriction triggers for the Lance Creek system.

\begin{tabular}{|c|c|c|}
\hline $\begin{array}{c}\text { Restriction } \\
\text { level }\end{array}$ & $\begin{array}{c}\text { Volume in Lance } \\
\text { Creek storage (ML) }\end{array}$ & $\begin{array}{c}\text { Lance Creek } \\
\text { storage (\% full) }\end{array}$ \\
\hline Level 1 & $1134 \mathrm{ML}$ & $27 \%$ \\
\hline Level 2 & $812 \mathrm{ML}$ & $19 \%$ \\
\hline Level 3 & $580 \mathrm{ML}$ & $14 \%$ \\
\hline Level 4 & $358 \mathrm{ML}$ & $9 \%$ \\
\hline
\end{tabular}

Table 2. Cost of restrictions ( $\$ / \mathrm{yr})$.

\begin{tabular}{|c|c|c|}
$\begin{array}{c}\text { Restriction } \\
\text { level }\end{array}$ & $\begin{array}{c}\text { Incremental cost of } \\
\text { restriction^ }\end{array}$ & $\begin{array}{c}\text { Total cost of } \\
\text { restriction }(T C R) *\end{array}$ \\
\hline Level 1 & $\$ 0$ & $\$ 0$ \\
\hline Level 2 & $\$ 30$ & $\$ 30$ \\
\hline Level 3 & $\$ 60$ & $\$ 90$ \\
\hline Level 4 & $\$ 200$ & $\$ 290$ \\
\multirow{2}{*}{ per residential connection } \\
sum of all lower levels, applied per residential connection
\end{tabular}


Equation (2) provides the total cost of the water from Melbourne ( Cost $\left._{\text {Melb }}\right)$ as the product of the volume delivered from the Melbourne system $\left(Q_{M e l b}\right)$ and the delivery cost unit $\left(T C M_{M C C_{\text {volume }}}\right)$ plus the fixed service cost unit $\left(T C M_{M C C_{\text {service }}}\right)$.

Cost $_{\text {Melb }}=Q_{\text {Melb }} \times T C M_{M C C_{\text {volume }}}+$ TCM $_{M C C_{\text {service }}}$

Environmental cost / benefit

Lance Creek downstream of the Lance Creek storage receives water in the model via storage spills and passing flows. The passing flow is equal to $100 \mathrm{ML}$ per year, when the volume in storage at the start of November is above $3000 \mathrm{ML}$. For the Lance Creek case study, it was assumed that a different value applies for flows supplied from regulated water and those provided from unregulated water. It is noted that CIE (2010) assumed a value of \$70/ML for additional storage spills and made no distinction between regulated and unregulated flows. Error! Reference source not found. presents the assumed spill and passing flow cost units which distinguish the greater value of stored environmental water (that can be delivered at any time) and the lower value spill water which is provided in a less structured manner.

Equation (3) provides the total environmental cost $\left(\right.$ Cost $\left._{\text {env }}\right)$ as the sum product of the spill volume $\left(Q_{\text {spill }}\right)$ and the spill cost unit $\left(T E C_{E C C_{\text {spill }}}\right)$, and the passing flow volume $\left(Q_{p f}\right)$ and the passing flow cost unit $\left(T E C_{E C C_{p f}}\right)$.

Cost $_{\text {env }}=Q_{\text {spill }} \times T E C_{E C C_{\text {spill }}}+Q_{p f} \times T E C_{E C C_{p f}}$

\section{INTEGRATED HYDROLOGY-ECONOMIC MODELLING SCENARIOS}

The five scenarios below were undertaken using the Lance Creek REALM model with the hydro-climatic inputs and demands described in Section 3 together with the economic cost calculations provided by Equation (1) to Equation (3). Note that these scenarios incrementally adjust the Melbourne supply from no supply to the Lance Creek system to the highest available supply when Lance Creek storage falls below the level 1 restriction threshold volume:

- No connection to Melbourne system.

- Melbourne supply triggered when storage is $300 \mathrm{ML}$ below the level 1 restriction threshold volume.

- Melbourne supply triggered when storage is 200 ML below the level 1 restriction threshold volume.

- Melbourne supply triggered when storage is $100 \mathrm{ML}$ below the level 1 restriction threshold volume.

- Melbourne supply triggered when storage is below the level 1 restriction threshold volume.

\section{INTEGRATED HYDROLOGY-ECONOMIC MODELLING RESULTS}

restrictions and increase the cost of supply from Melbourne. Note that the reason for the relatively small increases in cost of Melbourne supply compared to the larger decreases in cost of restrictions is due to the significant fixed component of the Melbourne supply costs (i.e. $T C M_{M C C_{\text {service }}}$ ).

summarises the modelling results in terms of the average monthly costs for restrictions, costs of supply from Melbourne, and environmental costs. Note that the negative environmental cost is referred to as a 'benefit' given that additional spills and passing flows in Lance Creek would be considered a positive rather than a negative outcome. It is also worth highlighting that the total environmental benefit is the additional passing flow and spill volume relative to the scenario with no connection to the Melbourne system. This is consistent with the approach adopted by CIE (2010). 
The scenarios are arranged from left to right with increasing volume of water supplied from Melbourne. The first (left-most) set of results relate to the scenario which assumes that there is no connection to the Melbourne system. In this scenario, the Lance Creek system would experience restrictions in 9 out 10 years on average under 2040 demand levels and 2040 medium climate change conditions. The modelling results show that the cost of restrictions would be approximately $\$ 160,000 /$ month; the highest cost amongst the scenarios considered. As expected, the other scenarios which have some level of access to the Melbourne system would alleviate restrictions and so reduce the cost of (deferring) restrictions and increase the cost of supply from

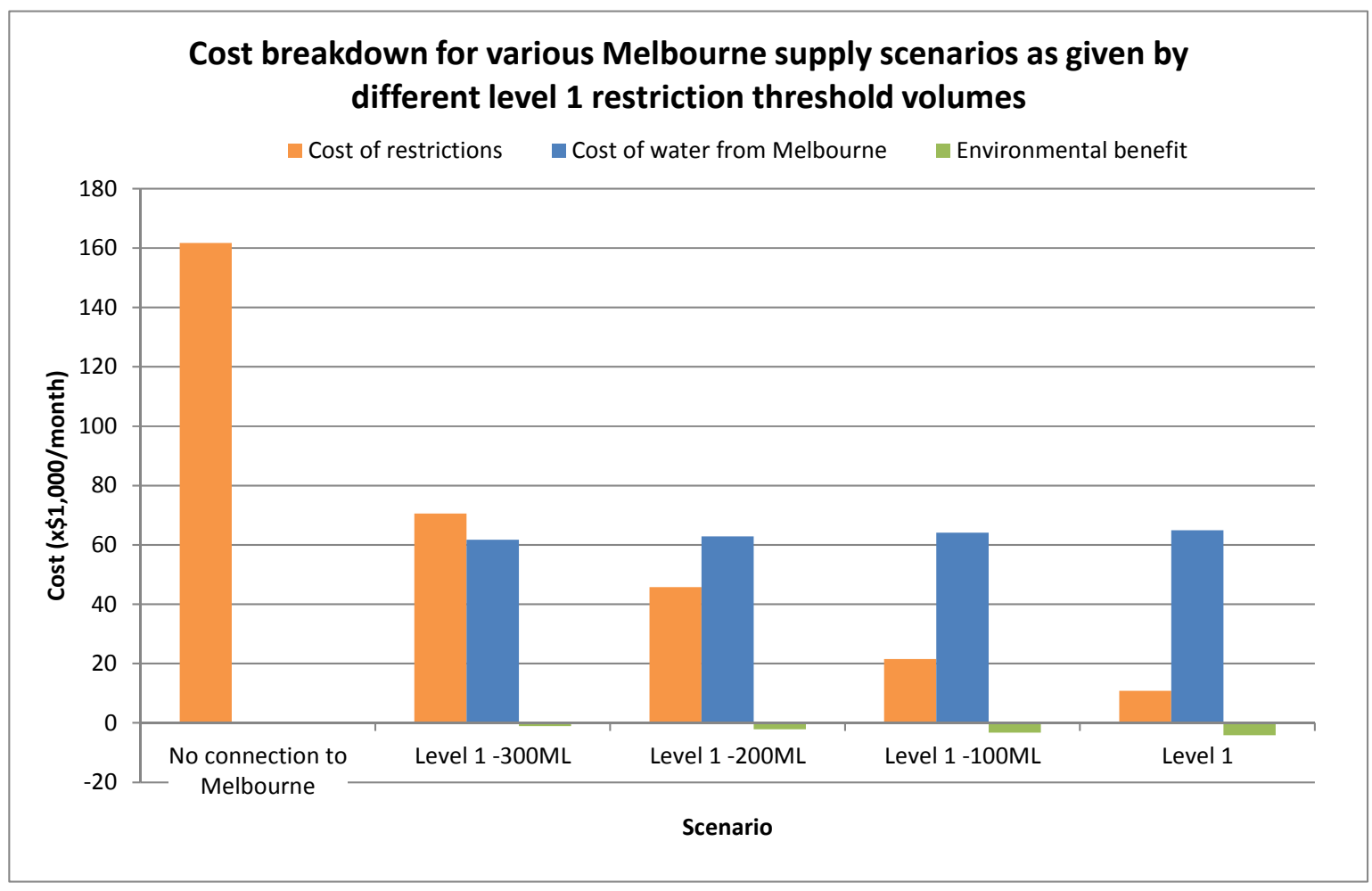

Figure 2. Cost breakdown for various Melbourne supply scenarios as given by different level 1 restriction threshold volumes.

Melbourne. Note that the reason for the relatively small increases in cost of Melbourne supply compared to the larger decreases in cost of restrictions is due to the significant fixed component of the Melbourne supply costs (i.e. $T C M_{M C C_{\text {service }}}$ ).

The key finding from this work is that there is a cross-over between the cost of restrictions and cost of water from Melbourne. This is shown to occur at a threshold volume between $300 \mathrm{ML}$ and $200 \mathrm{ML}$ below restriction level 1. The results also show an incremental increase in environmental benefit with increasing supply from Melbourne. This was largely due to the increased frequency of spills from Lance Creek Reservoir subsequent to times when Melbourne supply was occurring. That is, storage is drawn down less when Melbourne supply is reduced and so is less able to harvest local catchment inflows at a later date.

\section{DISCUSSION AND CONCLUSIONS}

The Lance Creek supply system has been used as a case study to demonstrate an approach for incorporating economic cost data into water resources modelling. Calculations for cost of restrictions, cost of water from Melbourne and environmental costs have been incorporated into the Lance Creek REALM model. The economic cost data used in this case study is based on work and assumptions drawn from other jurisdictions and not directly elicited from users in the Lance Creek system. This information has been used in the Lance Creek case study to demonstrate that economic cost data can be incorporated into water resource modelling as a proof-of-concept. It is recommended that such economic cost data and user preferences be based on systemspecific information with due consideration to the planning decisions of interest.

Further to the results presented in this paper, a number of other economic and non-water resource metrics could be incorporated into water resource modelling to provide a comprehensive estimate of total costs of operation 
for any given system. This could include the cost of security (which places a value on increased reliability of supply), power consumption and pumping costs, costs of operating water supply infrastructure (such as treatment plants), other environmental impacts (such as greenhouse gas emissions) and costs of groundwater pumping. This paper presents three different economic metrics to demonstrate that this type of information can be incorporated in a water resources model. A similar approach can be applied for other metrics as relevant for any given situation, assuming appropriate data is available to support the analysis.

In addition to providing more metrics resulting from scenario modelling, cost metrics could be used dynamically in the model to switch between different sources of supply based on costs. For instance, the results from the present study demonstrate that there is a cross-over between the cost of restrictions and the cost of water from Melbourne which may be used to optimise the timing and magnitude of supply from Melbourne or the need for other system augmentation plans in the future. Costs associated with non-market measures such as those linked to environmental flow components could be used to prioritise and re-order flows as conditions change. This study highlights the need for water corporations to optimise system operating rules in order to maximise sustainable outcomes.

\section{ACKNOWLEDGEMENTS}

This paper has been prepared with the support of the Victorian Department of Environment, Land, Water and Planning (DELWP) and South Gippsland Water. A special thanks to the reviewers for making major improvements to this paper.

\section{REFERENCES}

Bennett, J., Dumsday, R., Howell, G., Lloyd, C., Sturgess, N. and Van Raalte, L. (2008). The economic value of improved environmental health in Victorian rivers, Australasian Journal of Environmental Management 42, 131-148

Centre for International Economics (2010). Review of operating regime for Sydney Waters' desalination plant. DELWP (2016a). Guidelines for Assessing the Impact of Climate Change on Water Supplies in Victoria

DELWP (2016b). Water for Victoria. Prepared by State of Victoria Department of Environment, Land, Water and Planning.

DELWP (2016c). Victoria In Future 2016. Population and household projections to 2051. https://www.planning.vic.gov.au/_data/assets/pdf_file/0014/14036/Victoria-in-Future-2016-FINALweb.pdf. The State of Victoria Department of Environment, Land, Water and Planning.

eWater (2017). refer http://ewater.org.au/products/ewater-source/

Jacobs (2017). Incorporating cost of restrictions in water resources modelling discussion paper. Prepared for Department of Environment, Land, Water and Planning.

Kirby, J.M., Connor, J., Ahmad, M.D. and Mainuddin, M. (2014). Climate change and environmental water reallocation in the Murray-Darling Basin: Impacts on flows, diversions and economic returns to irrigation, Journal of Hydrology 518, 120-129.

Kirby, J.M., Connor, J., Ahmad, M.D., Gao, L. and Mainuddin, M. (2016). Irrigator and Environmental Water Management Adaptation to Climate Change and Water Reallocation in the Murray-Darling Basin, For Water Economics and Policy special issue on The Economics of Climate Change and Water, pp28.

Kuczera, G. (1992). Water supply headworks simulation using network linear programming. Advances in Engineering Software 14, 55-60.

Marsden Jacob Associates (2017). Draft discussion paper - dimensions and costs of urban water demand, shortages and restrictions. Prepared for Department of Environment, Land, Water and Planning.

Perera, B.J.C., James, B., and Kularathna M.D.U.P. (2005). Computer Software Tool REALM for Sustainable Water Allocation and Management. Journal of Environmental Management, 77, 291-300.

SGW (2017). Urban Water Strategy.

Victoria University of Technology and the Department of Natural Resources and Environment (2001). REALM User's Manual.

Wertenbroch, Klaus and Bernd Skiera (2002). Measuring Consumers' Willingness to Pay at the Point of Purchase, Journal of Marketing Research, 39 (May), 228-41.

Wheeler, S, A Zuo and H Bjornlund (2013). Farmer's climate change beliefs and adaptation strategies for a water secure future in Australia. Global Environmental Change 23, 537-547

Productivity Commission (2011). Australia's Urban Water Sector, Report No. 55, Final Inquiry Report, Canberra. 